\title{
Best Practices in Molecular Breast Imaging: A Guide for Technologists
}

\author{
Tiffinee N. Swanson, CNMT ${ }^{1}$, Thuy D. Tran, $\mathrm{CNMT}^{1}$, Lacey R. Ellingson, CNMT ${ }^{1}$, Michael K. O’Connor ${ }^{1}$, \\ Deborah J. Rhodes $^{2}$, Katie N. Hunt ${ }^{1}$, Amy Lynn Conners ${ }^{1}$, and Carrie B. Hruska ${ }^{1}$ \\ ${ }^{I}$ Department of Radiology, Mayo Clinic, Rochester, Minnesota; and ${ }^{2}$ Department of Internal Medicine, Mayo Clinic, \\ Rochester, Minnesota
}

\begin{abstract}
CE credit: For CE credit, you can access the test for this article, as well as additional JNMT CE tests, online at https://www.snmmilearningcenter.org. Complete the test online no later than March 2021. Your online test will be scored immediately. You may make 3 attempts to pass the test and must answer $80 \%$ of the questions correctly to receive $1.0 \mathrm{CEH}$ (Continuing Education Hour) credit. SNMMI members will have their CEH credit added to their VOICE transcript automatically; nonmembers will be able to print out a CE certificate upon successfully completing the test. The online test is free to SNMMI members; nonmembers must pay $\$ 15.00$ by credit card when logging onto the website to take the test.
\end{abstract}

\begin{abstract}
Molecular breast imaging (MBI) technologists must have a combination of both nuclear medicine skills and mammographic positioning skills. Currently, no formal programs offer this type of hybrid technologist training. The purpose of this perspective is to provide a best-practices guide for technologists performing MBI. Familiarity with best practices may aid in obtaining high-quality $\mathrm{MBI}$ examinations by decreasing the likelihood of image artifacts, positioning problems, and other factors that contribute to falsenegative or false-positive findings.
\end{abstract}

Key Words: molecular breast imaging; technologist guidebook; protocol

J Nucl Med Technol 2018; 46:3-11

DOI: $10.2967 /$ jnmt.117.204263

M olecular breast imaging, or MBI, is a promising nuclear medicine technique shown to have value in detecting cancer that is occult on the conventional technologies of mammography and ultrasound. Interest in MBI is growing because of recent clinical trials showing that adding MBI to mammography increases cancer detection over mammography alone in women with dense breasts $(1,2)$. Although MBI has been used as a general term to describe several types of nuclear medicine systems to image the breast (3), in this work we refer to MBI as a dedicated $\gamma$-camera for imaging single-photon emitters. Because MBI is a relatively new technology, there is considerable variation in its use in clinical practice, and the literature provides little guidance for technologists performing this modality.

MBI is unique in that a combination of nuclear medicine skills and mammographic positioning techniques is essential

Received Nov. 3, 2017; revision accepted Dec. 29, 2017.

For correspondence or reprints contact: Tiffinee N. Swanson, CNMT, Gonda 2 130BII, Department of Radiology, Mayo Clinic, 200 First St. S.W., Rochester, MN 55905.

E-mail: swanson.tiffinee@mayo.edu

Published online Feb. 2, 2018.

COPYRIGHT (c) 2018 by the Society of Nuclear Medicine and Molecular Imaging. to obtain a successful examination. Nuclear medicine training, which includes knowledge of $\gamma$-camera operations, proper injection technique, safe handling of radiopharmaceuticals, and radiation safety considerations, is typically required per state regulations for technologists performing nuclear medicine examinations. Training in proper mammographic positioning is also important, as poor positioning of the breast may result in nonvisualization of cancers not included in the imaging field of view (FOV) $(4,5)$. Thus, knowledge of both modalities is required for high-quality MBI examinations.

At present, there is an educational gap for hybrid imaging technologies across radiology, specifically regarding PET/CT and PET/MRI (6). MBI also falls into this hybrid category, and currently there are no formal education programs offering this training for MBI technologists. Our institution has been performing MBI since 2004, with over 6,000 examinations performed to date. In this time, we have uncovered several key factors that affect image quality. The purpose of this perspective is to provide a best-practices guide for technologists performing MBI.

\section{QUALITY CONTROL}

Quality control testing of the imaging system should be performed daily to ensure the MBI equipment is operating properly. A daily uniformity flood test should be conducted before use on patients. Because of the inability to exchange collimators on MBI systems, the daily uniformity flood scan is always acquired extrinsically. Per National Electrical Manufacturers Association specifications, integral uniformity should be $5 \%$ or less (7). Uniformity calibrations should be performed when integral uniformity is out of range, per manufacturer recommendations. Daily uniformity flood scans should be repeated after calibrations to ensure that uniformity falls within range.

\section{EXAMINATION PREPARATION}

The first step to obtaining a high-quality MBI examination is adequate technologist preparation. Before imaging, 
the technologist can prepare by reviewing the patient's breast health history, including the prior breast biopsy and surgical history. This should also include verification of the indication for imaging. Common indications for MBI include supplemental screening for women with dense breast tissue (95\% of our practice), problem solving for indeterminate imaging findings, evaluation of response to neoadjuvant chemotherapy, and imaging in those who need but cannot undergo MRI because of contraindications such as a pacemaker, contrast allergy, renal failure, claustrophobia, or large body habitus $(8-10)$. The technologist should review the patient's prior mammogram or MBI scan if available for comparison.

It is important for the technologist to recognize special considerations that may adversely affect the MBI examination. MBI should not be scheduled adjacent to other nuclear medicine studies or therapies that may interfere with imaging (Tables 1 and 2). Whenever possible, it is recommended that MBI be performed before biopsy to prevent postprocedural inflammatory uptake from confounding interpretation at the biopsy site (10). However, if MBI is performed after biopsy, the interpreting radiologist should be made aware that a biopsy was recently performed. The technologist should also know of the breast-positioning modifications that might be required after biopsy.

MBI has more dead space at the edge of the FOV than digital mammography (8 vs. $4 \mathrm{~mm}$, respectively). For this reason, lesions in the chest wall or in the posterior axillary tail may be difficult to visualize with MBI. Taking care in positioning to include posterior tissue may help to bring a posterior lesion into the MBI camera's FOV. Additionally, certain patient conditions, such as Parkinson disease, arm paralysis, dystonia, or other movement disorders, may make it difficult for the patient to remain comfortable and stationary or to otherwise fulfill the examination requirements. In these cases, MBI may still be performed, but the technologist should ensure that the patient and ordering provider are aware of the examination requirements. The technologist should be prepared to modify the examination (allow for extra time for additional views, request additional personnel or positioning aids such as pillows for added comfort) and tell the patient and the interpreting radiologist about any modifications.

\section{PATIENT PREPARATION}

Uptake of ${ }^{99 \mathrm{~m}} \mathrm{Tc}$-sestamibi is lower in the breast than in other organs, comprising less than $1 \%$ of the administered dose, and depends on blood flow to organs such as the liver, heart, and kidneys and to muscle tissue (11). We have found that fasting and warming of the upper torso to divert blood flow away from these other areas increases uptake in breast tissue (12). A fast of at least $3 \mathrm{~h}$ before MBI is recommended, though it is not a requirement for the examination. If fasting is used, special considerations may be needed for diabetic patients. Patients are encouraged to drink water to stay hydrated for injection and may have diet soda, black coffee, and tea with no cream or sugar. By decreasing hepatic blood flow, fasting increases the amount of $99 \mathrm{~m} \mathrm{Tc}-$ sestamibi available in the breast by approximately $25 \%$ (12). The patient's shoulders should also be wrapped in a warm blanket for at least $5 \mathrm{~min}$ before injection to further improve breast uptake by increasing peripheral blood flow to the upper torso (12). The patient should change into a gown, removing all clothing from the waist up, to better facilitate imaging. Deodorants, lotions, powders, and jewelry (such as necklaces) do not need to be removed for the MBI examination.

TABLE 1

Guidelines for Waiting Periods Between Imaging Procedures Performed Before MBI Examination

\begin{tabular}{|c|c|c|c|}
\hline Modality & Procedure & Administered dose & $\begin{array}{l}\text { Recommended } \\
\text { waiting period }\end{array}$ \\
\hline CT & With or without contrast & & None \\
\hline MRI & With or without contrast & & None \\
\hline \multirow[t]{3}{*}{ PET } & ${ }^{18} \mathrm{~F}-\mathrm{FDG}$ & $555 \mathrm{MBq}(15 \mathrm{mCi})$ & $>12 \mathrm{~h}$ \\
\hline & ${ }^{11} \mathrm{C}$-choline & $370-740 \mathrm{MBq}(10-20 \mathrm{mCi})$ & $>2 \mathrm{~h}$ \\
\hline & ${ }^{13} \mathrm{~N}$-ammonia & $370-740 \mathrm{MBq}(10-20 \mathrm{mCi})$ & $>1 \mathrm{~h}$ \\
\hline \multirow[t]{9}{*}{ Nuclear medicine } & 99mTc-sestamibi for parathyroid or cardiac studies & $370-1,110 \mathrm{MBq}(10-30 \mathrm{mCi})$ & None* $^{*}$ \\
\hline & 99mTc-radiopharmaceuticals, intravenous & $>740 \mathrm{MBq}(20 \mathrm{mCi})$ & $>24 \mathrm{~h}$ \\
\hline & & $>370 \mathrm{MBq}(10 \mathrm{mCi})$ & $>18 \mathrm{~h}$ \\
\hline & & $>185 \mathrm{MBq}(5 \mathrm{mCi})$ & $>12 \mathrm{~h}$ \\
\hline & & $<185 \mathrm{MBq}(5 \mathrm{mCi})$ & $>6 \mathrm{~h}$ \\
\hline & 99mTc-radiopharmaceuticals, oral & $<185 \mathrm{MBq}(5 \mathrm{mCi})$ & None \\
\hline & 123/-based radiopharmaceuticals & $>370 \mathrm{MBq}(10 \mathrm{mCi})$ & $>2 \mathrm{~d}$ \\
\hline & ${ }^{111}$ In- and ${ }^{67} \mathrm{Ga}-$ based radiopharmaceuticals & $185-370 \mathrm{MBq}(5-10 \mathrm{mCi})$ & $>3 d$ \\
\hline & & $<37 \mathrm{MBq}(1 \mathrm{mCi})$ & $>24 \mathrm{~h}$ \\
\hline
\end{tabular}

These are general guidelines and in some cases may overestimate waiting period needed, depending on biologic distribution of radiopharmaceutical.

${ }^{*}$ In cases of prior administration of ${ }^{99 m T c}$-sestamibi for cardiac or parathyroid studies, reduced (or no dose) of ${ }^{99 \mathrm{mT}} \mathrm{Tc}$-sestamibi may be used, depending on residual activity from prior study. 
TABLE 2

Guidelines for Waiting Periods Between MBI Examination and Other Imaging Procedures

\begin{tabular}{|c|c|c|c|}
\hline Modality & Procedure & Administered dose & $\begin{array}{l}\text { Recommended } \\
\text { waiting period }\end{array}$ \\
\hline CT & With or without contrast & & None \\
\hline $\mathrm{MRI}$ & With or without contrast & & None \\
\hline PET & All radiopharmaceuticals & & None \\
\hline \multirow[t]{9}{*}{ Nuclear medicine } & $\begin{array}{l}99 \mathrm{~m} \text { Tc-sestamibi for parathyroid (or cardiac } \\
\text { rest only) studies }\end{array}$ & $370-1,110 \mathrm{MBq}(10-30 \mathrm{mCi})$ & None* \\
\hline & 99mTc-radiopharmaceuticals, intravenous or oral & $>740 \mathrm{MBq}(20 \mathrm{mCi})$ & $>12 \mathrm{~h}$ \\
\hline & & $>370 \mathrm{MBq}(10 \mathrm{mCi})$ & $>24 \mathrm{~h}$ \\
\hline & & $>185 \mathrm{MBq}(5 \mathrm{mCi})$ & $>24 \mathrm{~h}$ \\
\hline & & $<185 \mathrm{MBq}(5 \mathrm{mCi})$ & $>36 \mathrm{~h}$ \\
\hline & 99mTc-sulfur colloid (sentinel node) & $<19 \mathrm{MBq}(500 \mu \mathrm{Ci})$ & $>24 \mathrm{~h}$ \\
\hline & 123I-based radiopharmaceuticals & $>370 \mathrm{MBq}(10 \mathrm{mCi})$ & None \\
\hline & & $<37 \mathrm{MBq}(1 \mathrm{mCi})$ & $>24 \mathrm{~h}$ \\
\hline & ${ }^{111}$ In- and ${ }^{67} \mathrm{Ga}-$ based radiopharmaceuticals & & None \\
\hline
\end{tabular}

These are general guidelines and in some cases may overestimate waiting period needed, depending on biologic distribution of radiopharmaceutical.

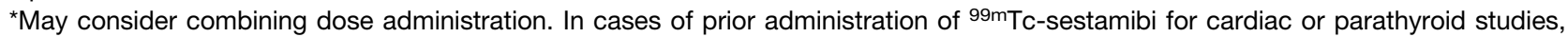
reduced (or no dose) of ${ }^{99 \mathrm{~m} T c-s e s t a m i b i}$ may be used, depending on residual activity from prior study.

The technologist should thoroughly explain the procedure to the patient before starting the MBI examination. Patient education includes describing the injection of ${ }^{99 \mathrm{~m}} \mathrm{Tc}$-sestamibi and the rare potential for mild side effects (e.g., flushing, rash, injection site inflammation, or a brief metallic taste (13)), explaining the imaging procedure, and telling the patient how she will receive the examination results. As with any nuclear medicine procedure, the technologist should verify the patient's identity in 2 ways, such as name and date of birth, and that the patient is not pregnant or breast feeding. Patients who are breast feeding should discontinue doing so and discard expressed milk according to institutional guidelines. Technologists should verify with the patient the indication for the examination and ask the patient if she has any areas of breast concern.

If the patient reports an area of breast concern or if an area of concern is noted during the technologist's assessment of prior imaging history, the affected side should be imaged first in case the patient cannot tolerate the entire examination. It is also important to identify the specific

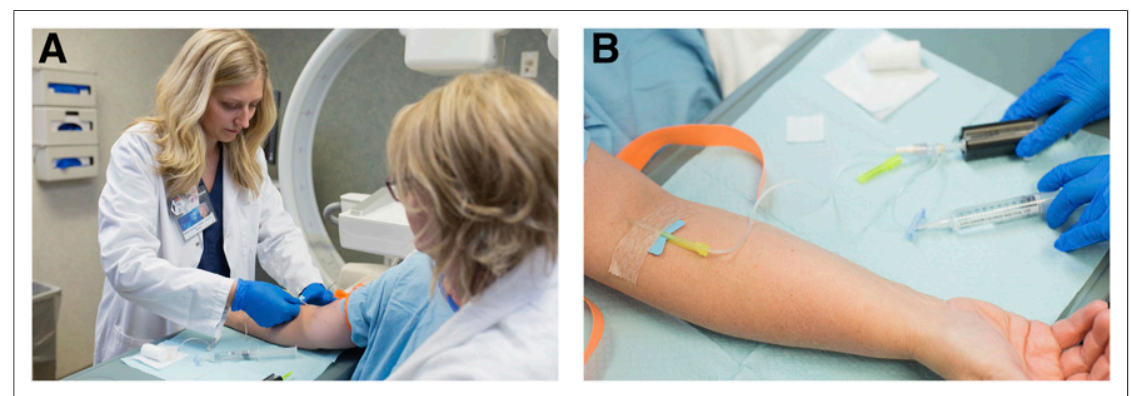

FIGURE 1. (A) Intravenous injection of ${ }^{99 m} \mathrm{Tc}$-sestamibi via butterfly needle. (B) Radiotracer in low-adhesion syringe (encased in syringe shield) connected to $10-\mathrm{mL}$ saline flush for injection. area of concern in the affected breast to confirm that it will be included in the imaging FOV. Occasionally, an additional or substitute view may be needed to include an area of concern.

Reporting of the patient's menopausal status, phase of menstrual cycle, and exogenous hormone use may aid the radiologist in image interpretation. These hormonal factors may influence background parenchymal uptake, which describes the level of radiotracer uptake in normal fibroglandular tissue $(14,15)$. In pre- and perimenopausal women, the menopausal status and last menstrual period should be reported to the radiologist interpreting the examination. Premenopausal women may benefit from scheduling imaging during days $7-14$ of their menstrual cycle to decrease the likelihood that background parenchymal uptake may affect interpretation, with the first day of the last menstrual period considered as day 1. Postmenopausal status should also be reported and can be defined as surgical sterilization (bilateral oophorectomy) or more than $1 \mathrm{y}$ since the last menstrual period. Recording patient use of medications that could influence background parenchymal enhancement, such as contraceptive medications, postmenopausal systemic hormonal therapies (estrogens and progestogens), and antiestrogen therapies (tamoxifen, raloxifene, and aromatase inhibitors), may also aid in interpretation.

\section{RADIOPHARMACEUTICAL INJECTION}

The primary imaging agent used for MBI is ${ }^{99 \mathrm{~m} T c-s e s t a m i b i . ~ A l t h o u g h ~}$ the exact mechanism of uptake is 

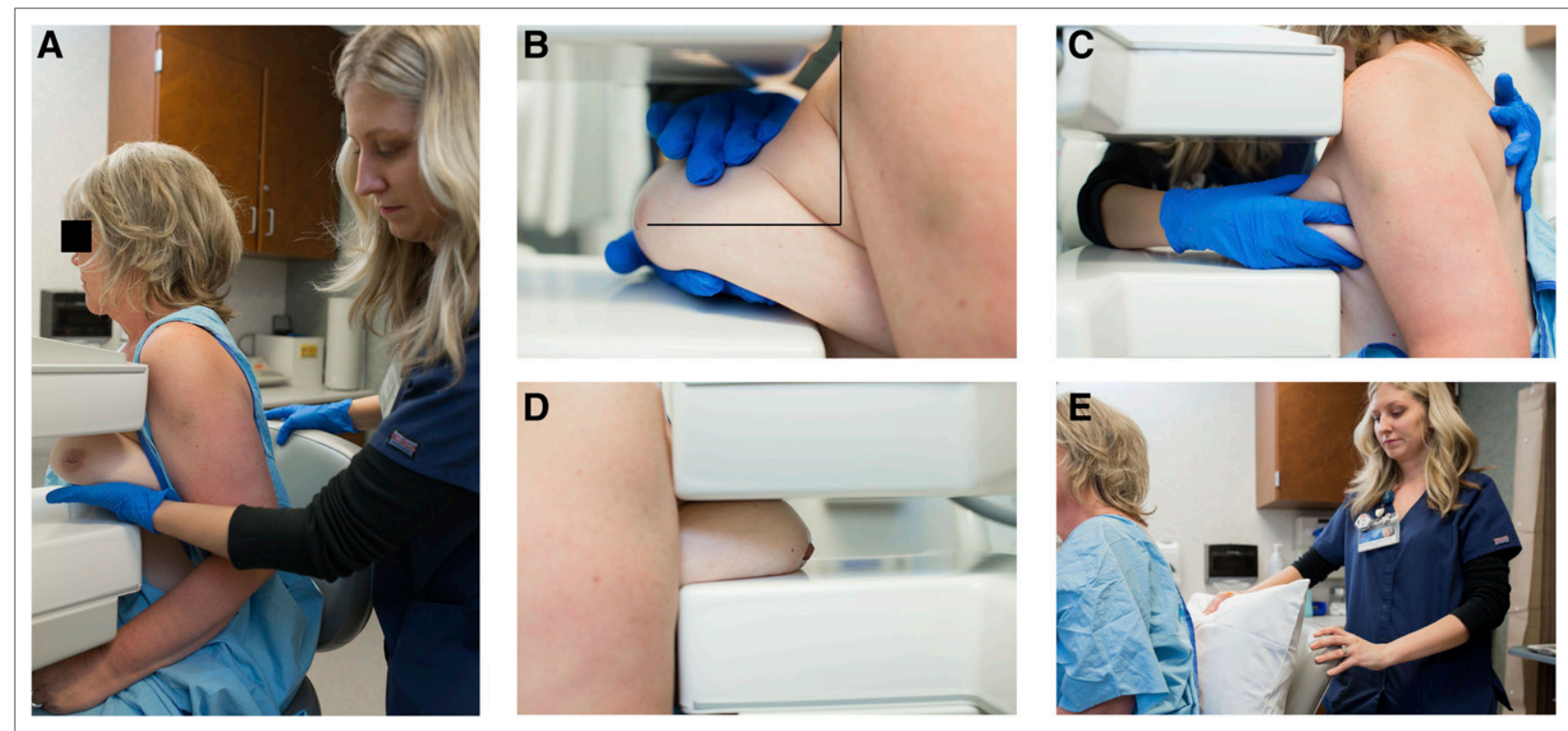

FIGURE 2. Proper breast positioning for craniocaudal view. (A) Patient is seated in chair with shoulder relaxed and arms resting in lap. While breast is guided to camera, IMF is lifted until nipple extends perpendicular to chest wall. (B) With nipple extending perpendicular to chest wall, 2 hands are used to lift breast onto detector. (C) Lateral aspect of breast is pulled and anchored into FOV while compression is slowly applied. (D) Compression is applied in this craniocaudal view. (E) Patient's back is supported with pillows to increase comfort and prevent motion.

unknown, it is hypothesized that uptake of ${ }^{99 m}$ Tc-sestamibi in breast tumors is relative to mitochondrial metabolism or the negative membrane potential of tumor cells (16). For dualhead MBI systems that use semiconductor-based detectors, a prescribed activity of $300 \mathrm{MBq}(8 \mathrm{mCi})$ has been validated in 2 clinical trials $(1,2)$. Because it delivers a radiation dose below background radiation levels, this activity is considered acceptable for screening (17). The prescribed activity does not need to be adjusted on the basis of patient weight or breast size (18).

${ }^{99 \mathrm{~m}} \mathrm{Tc}$-sestamibi has properties that promote adhesion to the syringe surface, specifically the plunger of the syringe. For this reason, it is recommended that ${ }^{99 \mathrm{~m}} \mathrm{Tc}$-sestamibi be supplied via a low-adhesion syringe to minimize the residual activity remaining in the syringe after injection. In a previous evaluation, we compared residual activities obtained with various type of syringe and identified a brand with considerably low adhesion of sestamibi and the lowest residual activity among the brands evaluated (DPS, $3 \mathrm{~cm}^{3}$; DuoProSS Meditech Corp.) (19). For imaging practices that receive unit doses from a central pharmacy, low-adhesion syringes should be requested for all ${ }^{99 \mathrm{~m} T c-s e s t a m i b i}$ doses. Preinjection activity and time of measurement, injection time, residual activity in the syringe after injection, and time of residual measurement should be recorded to allow for calculation of the administered activity to the patient. According to previous work (19), the 10th-90th percentile for residual activities using the recommended low-adhesion brand of syringe was
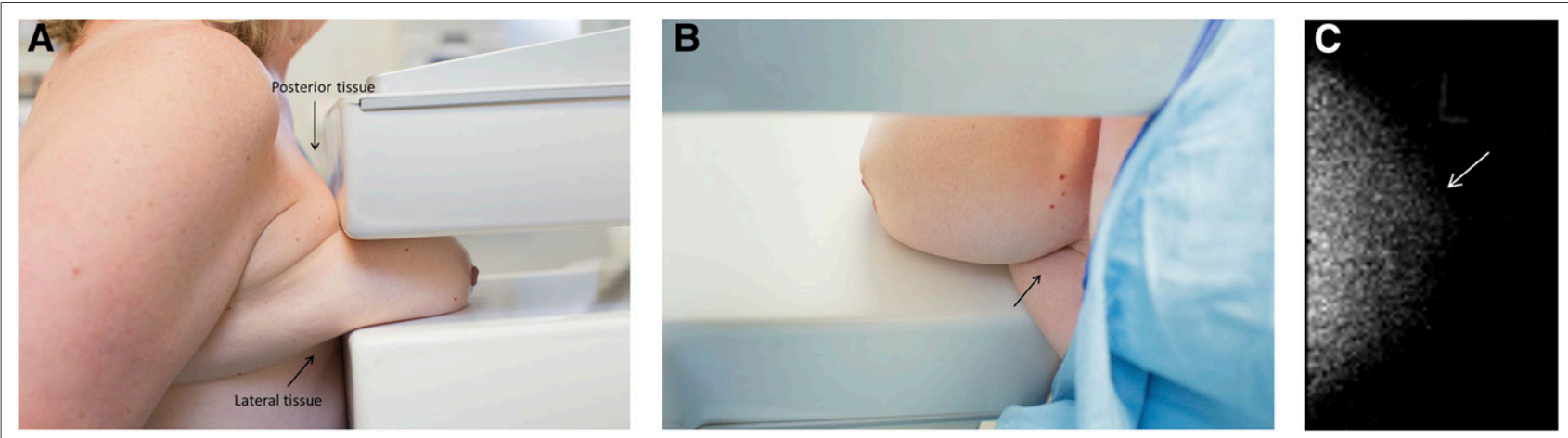

FIGURE 3. Improper breast positioning for craniocaudal view. (A) Lateral and posterior breast tissue is not fully included in FOV. (B) Camera is lower than IMF, creating fold underneath breast and causing nipple to point inferiorly. (C) Motion during craniocaudal (CC) acquisition creates appearance of blurred edge to breast tissue on resultant image. 


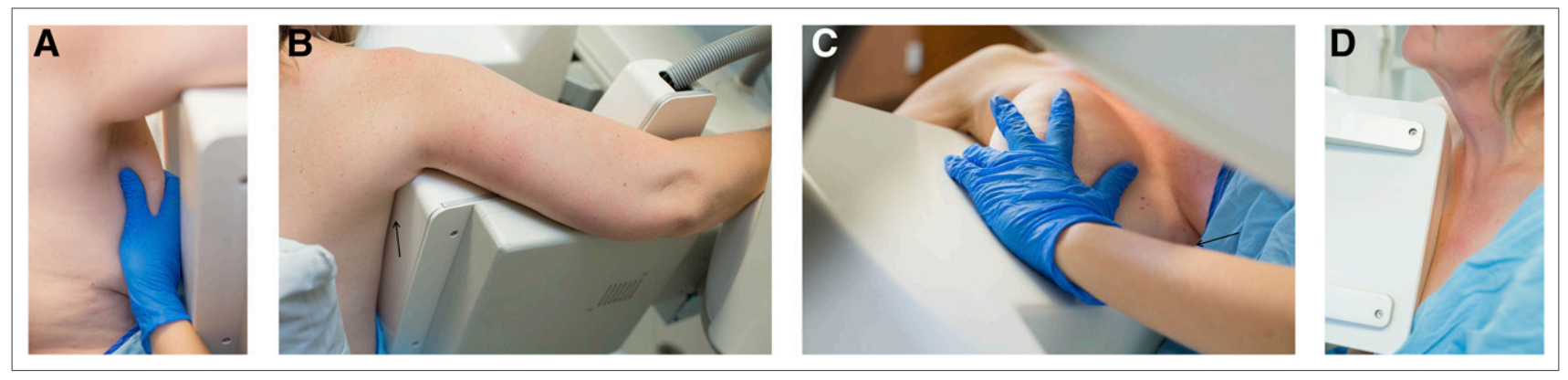

FIGURE 4. Proper breast positioning for MLO view. (A) Detector angle matches angle of pectoral muscle. (B) Patient's arm is on top of detector, with no gap (arrow) between detector and chest. (C) IMF (arrow) is opened by lifting breast up and away from chest wall. (D) In a medial view of the MLO with compression applied, there is no gap between upper detector and chest wall, and corner of detector rests below clavicle.

$2.2 \%-7.7 \%$. Thus, if residual activity consistently exceeds $7 \%$ of the dispensed activity, the prescribed activity may need to be increased to achieve the appropriate administered activity.

The radiotracer is administered intravenously to the patient using a butterfly needle or indwelling intravenous catheter, followed by a $10-\mathrm{mL}$ saline flush as illustrated in Figure 1. It is highly recommended that the straightneedle-stick technique be avoided both to minimize the risk of infiltration into the arm and to allow for flushing of the syringe. Once the radiotracer is injected into the patient, the butterfly needle or indwelling catheter can be immediately removed and the patient's injection site bandaged. All injection materials should be disposed of in a shielded radioactive-sharps container with biohazard markings.

The antecubital fossa is the most commonly selected site for venous access. In patients with known breast cancer or a previous axillary lymph node dissection, the contralateral arm may be recommended. Normal lymph nodes may take up radiotracer even in the absence of infiltration. For this reason, our practice does not require the use of foot injections in cases of bilateral breast cancer, as uptake may be seen in benign lymph nodes even when no dose infiltration occurs.

Rarely, patients may show symptoms of a vasovagal response at the time of injection, such as vertigo, shakiness, or pale skin. If this occurs, the patient should be placed in a reclining position with the feet elevated and be given fluids. If hypoglycemia is suspected, patients may be given sugar via juice, crackers, or other means. If possible to safely do so, sugars should be given after injection. Any changes that fall outside the normal patient preparation procedure for the MBI examination should be documented.

\section{CONTRAINDICATIONS RELATIVE TO OTHER IMAGING PROCEDURES}

Tables 1 and 2 present guidelines for waiting periods between PET, nuclear medicine, CT, or MRI procedures following molecular breast imaging and vice versa. The most common conflict is between an MBI study and a following sentinel node study. Because of the low administered activity used for a sentinel node study (typically, $<18,500 \mathrm{kBq}$ [500 $\mu \mathrm{Ci}]$ of ${ }^{99 \mathrm{~m}} \mathrm{Tc}$-sulfur colloid), a gap of at least $24 \mathrm{~h}$ between the MBI study and sentinel node study is recommended to ensure that residual activity from the MBI study does not interfere with sentinel node localization.

Although some patients have reported mild allergic reactions to some of the agents in the sestamibi kit (10), there are no contraindications to the administration of sestamibi itself. Sestamibi is administered at a tracer dose level (maximal dose, $<1 \mathrm{mg}$ ), not at a pharmacologic dose level. Pharmacologic effects have been reported to occur at doses of more than 600 times the maximal dose used in clinical studies (10).
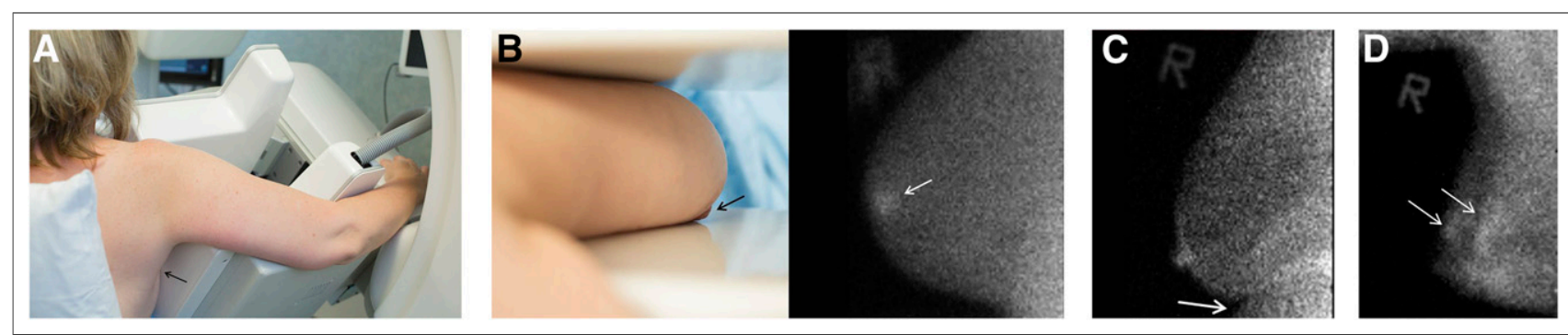

FIGURE 5. Improper breast positioning for MLO view. (A) Gap (arrow) between detector and chest indicates improper positioning. (B) MLO view of breast with nipple not positioned in profile (black arrow) creates appearance of pseudo lesion (white arrow) on resultant image. Radioactive "R" marker indicates laterality. (C) In patient with larger body habitus in whom IMF is not open, abdominal tissue is included in FOV (arrow). (D) Motion on MLO view creates appearance of 2 outlines of breast. 


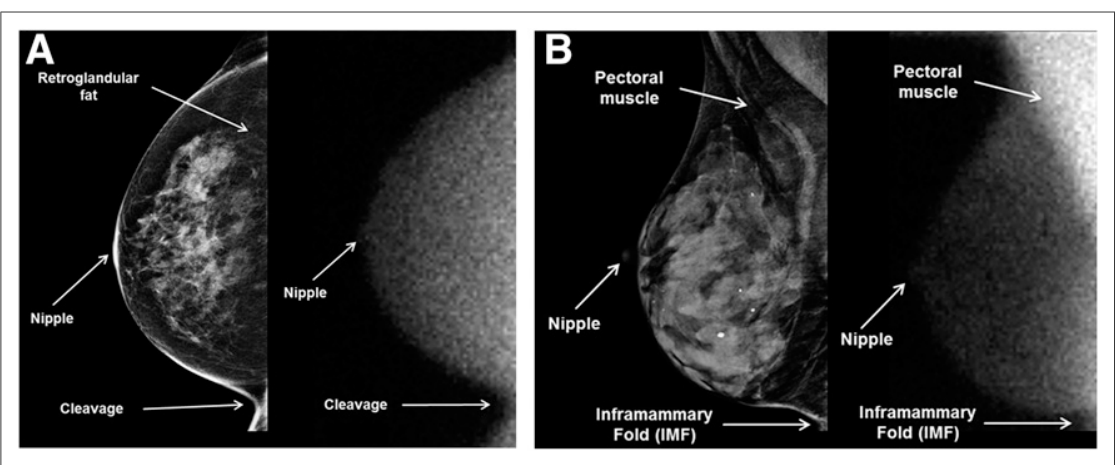

FIGURE 6. Proper breast positioning on mammography (left) and MBI (right). (A) Presence of cleavage and all lateral breast tissue while nipple is kept in profile indicates properly positioned breast for craniocaudal view. (B) Presence of pectoral muscle, nipple in profile, and open IMF indicate properly positioned breast for MLO view.

\section{IMAGING}

Because ${ }^{99 \mathrm{~m} T c-s e s t a m i b i}$ clears from the bloodstream rapidly (within 2-3 min (11)) and is taken up largely by first-pass extraction, with minimal redistribution (20), breast imaging may begin within 5 min after injection. Minor delays between injection and imaging are not problematic because ${ }^{99 \mathrm{~m}}$ Tc-sestamibi uptake stays relatively constant in the breast over the examination duration, with minimal washout over $1 \mathrm{~h}(21)$.

For the MBI examination, the patient is seated in an imaging chair, preferably a specialized mammography chair with wheels that lock into place and an adjustable back rest that can be pushed forward or reclined (JZ Imaging and Consulting). The patient should sit up straight as far back in the chair as possible and relax the shoulders. The chair should be guided to the camera and the patient's breast centered in the FOV.

A standard MBI examination comprises bilateral craniocaudal and mediolateral oblique (MLO) views. In our practice, views are typically acquired for $10 \mathrm{~min}$ each, although other practices have reported using shorter acquisitions (22). It is recommended that technologists have handson training in at least 25 mammography examinations before performing MBI, because the landmarks for breast positioning are the same as in mammography (23). If training in mammography is not feasible, an alternative approach would be to perform at least $25 \mathrm{MBI}$ examinations with an experienced MBI technologist. If applicable, begin imaging on the side of the affected breast as previously suggested.

For the craniocaudal view, the camera is positioned at $0^{\circ}$. The patient should rest her arms comfortably in her lap to keep the shoulders relaxed. Positioning for the craniocaudal view is done as follows. Placing a hand under the breast at the level of the inframammary fold (IMF), the technologist lifts the breast slightly until the nipple extends out at a level perpendicular to the chest wall. The camera height is raised or lowered to meet the elevated IMF. The technologist pulls the breast tissue onto the camera using both hands while simultaneously having the patient lean toward the camera. The craniocaudal view should include the breast tissue from the medial cleavage to meet the axilla laterally, with the nipple kept in profile. If the nipple is not in profile, the machine height must be adjusted; the nipple will typically be positioned in the direction of any missing breast tissue (i.e., if the nipple is positioned underneath the breast, the inferior breast tissue is likely not fully included). If uncorrectable, as can be common in patients with prior breast surgery, this anomaly should be reported to the radiologist before interpretation as it may create the appearance of a pseudo lesion. While the lateral aspect of the breast is pulled forward, enough compression is slowly applied to keep the breast immobile but the patient comfortable for the duration of the acquisition. Patients who have undergone a recent breast biopsy may tolerate less compression. Figure 2 illustrates proper breast positioning for the craniocaudal view, and Figure 3 illustrates improper breast positioning for the craniocaudal view.

For the MLO view, the camera is at approximately $45^{\circ}$, with the patient's arm resting on top of it. Typically, patients with a longer trunk and smaller breasts require a greater angle whereas patients with a shorter trunk and larger breasts require a lesser angle. Positioning for the MLO view is done as follows. From behind the patient, the technologist matches the detector angle with the angle of the pectoral muscle. Next, the pectoral muscle and shoulder are guided into the camera so that the patient's axilla is flush with the detector, with no gaps between the detector and the chest. From the front of the patient, the technologist guides the breast tissue between the detectors while having the patient lean into the camera. The breast is pulled up so that the nipple again extends perpendicular to the chest wall, and the breast is pulled away from the chest to open the IMF. The camera height is adjusted so that axillary tissue, the bottom of the breast, and the IMF can be included in the FOV. While the nipple is kept in profile, compression is slowly applied to immobilize the breast. If the compression hits the patient's shoulder before the IMF, the patient should be reminded to relax her shoulder, and if this attempt is not successful, the camera angle is increased by a few degrees. For a patient of larger body habitus, the chair may need to be slightly pulled away from the camera, and the patient may need to lean further to keep the abdominal tissue outside the FOV. Figure 4 illustrates proper breast positioning for the MLO view, and Figure 5 illustrates improper breast positioning for the MLO view.

Breast positioning should be like that in the mammography standards to ensure maximal breast visualization, 
except for the compression force (MBI recommended maximum, $67 \mathrm{~N}[15 \mathrm{lb}]$; mammography recommended maximum, 51-158 N [11-36 lb]). The patient's most recent mammography images should be used to aid in proper breast positioning, with recognition that the increased dead space and decreased compression force of MBI may make the breast appear slightly different. The craniocaudal view should include the area from cleavage to where the lateral breast meets the axilla, and the MLO view should include the pectoralis muscle and have an open IMF (Fig. 6). Because the pectoralis muscle does not always have avid $99 \mathrm{~m}$ Tc-sestamibi uptake, comparison imaging is helpful for assessing positioning. Each acqui- sition should be labeled using radioactive markers to indicate laterality.

The patient's back should be supported with pillows to prevent motion artifacts (Fig. 2E). Movement of the breast during the acquisition results in a blurred image. Although slight motion may not be detected, significant motion will create a blurred edge to the breast tissue (Figs. 3C and 5D). During imaging, the patient's torso should remain motionless, but the patient may move her head as needed and breathe normally. Imaging should be repeated if there is visible motion. Offering a distraction such as a television show to watch can help patients pass the time during imaging.

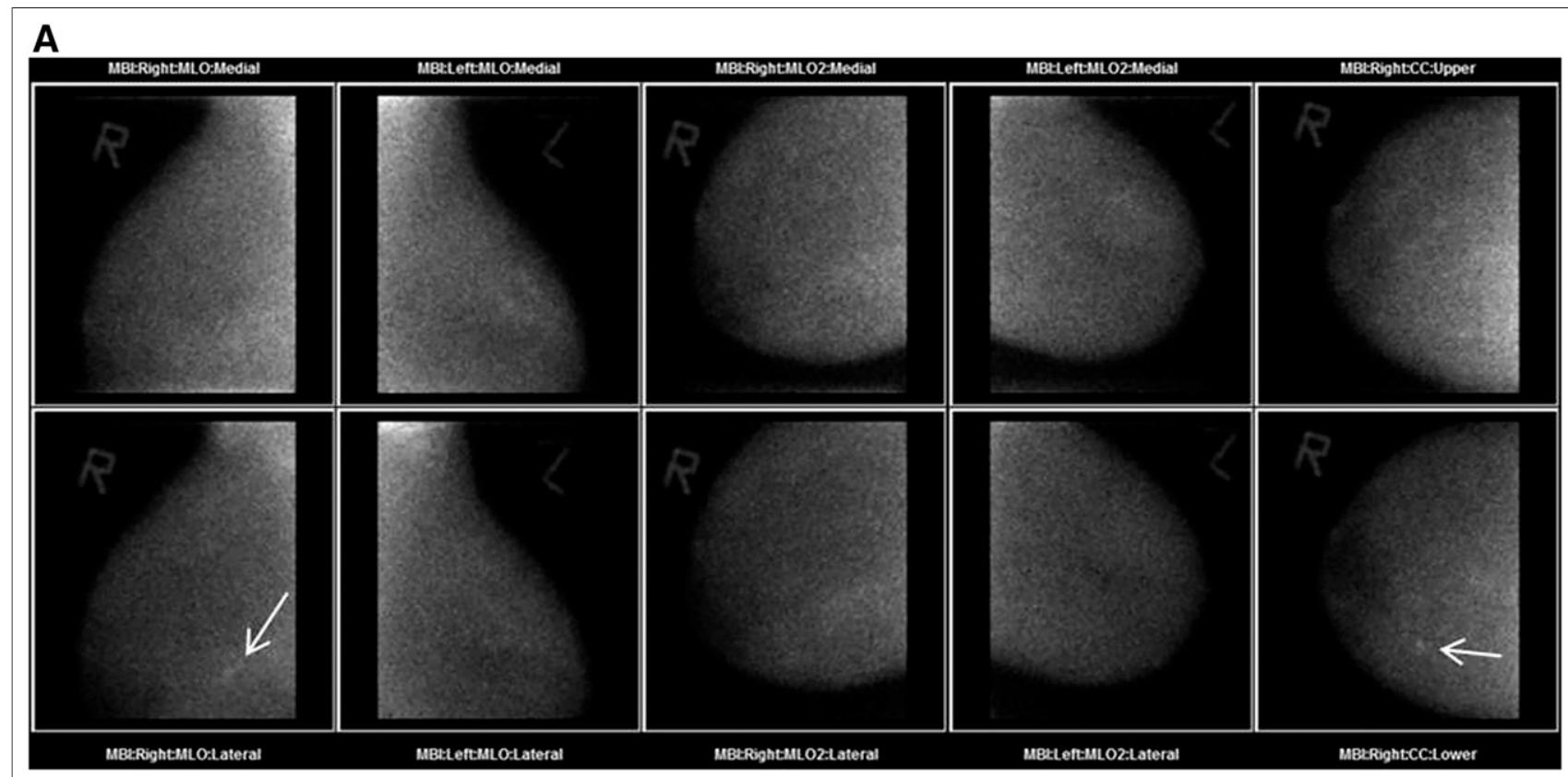

B

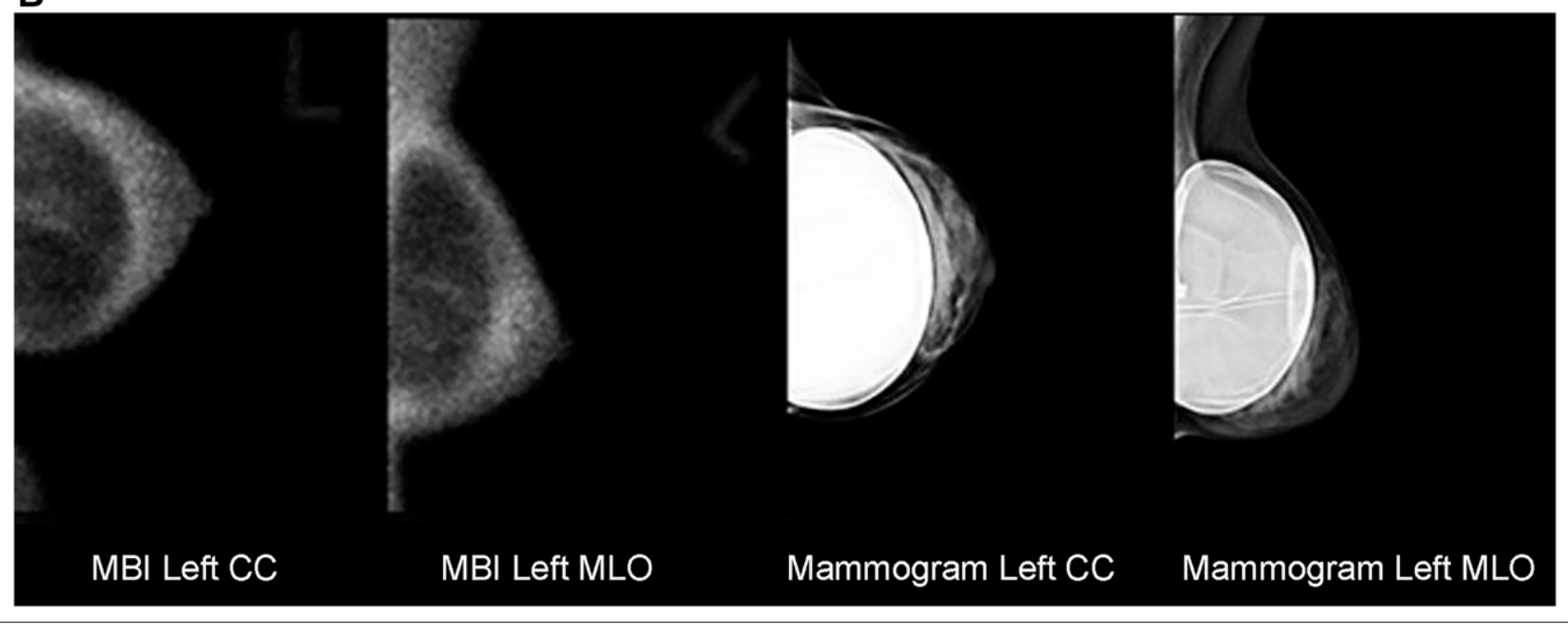

FIGURE 7. Common imaging variants. (A) Tiled MLO views were performed on patient whose breast size exceeded MBI FOV, with additional craniocaudal (CC) view being acquired to assess area of uptake (arrow). (B) Breast implants appear photopenic on $\mathrm{MBI}$ views. 


\section{COMMON VARIANTS}

The size of a typical detector for MBI is $20 \times 16 \mathrm{~cm}$ or $24 \times 16 \mathrm{~cm}$, compared with $24 \times 29 \mathrm{~cm}$ for mammography. This smaller size of MBI detectors may make it necessary to perform tiled MLO views if the breast size exceeds the FOV (Fig. 7). To minimize the length of the examination for patients who require tiled views, our practice acquires bilateral MLO images of the superior and inferior breast tissue in place of the standard bilateral craniocaudal and MLO views (Fig. 7). If an area of uptake is seen on the MLO views, an additional craniocaudal view of the area of uptake is acquired to help the radiologist determine the location of the lesion. When tiled views are obtained, it is important to include the nipple in at least 1 view.

The MBI protocol for patients with breast implants does not differ from the standard bilateral craniocaudal and MLO views. Unlike mammography, MBI does not require additional imaging with implant-displaced views. Implants typically appear photopenic on the MBI examination (Fig. 7). Often, breast implants are better visualized on the lowerdetector views because the implants are positioned closer to the lower detector than to the upper detector.

Patients with pacemakers can also undergo MBI. Like breast implants, the pacemaker appears photopenic and is often better visualized on one detector than the other.

Some moles have increased vascularity and therefore take up more ${ }^{99 \mathrm{~m}} \mathrm{Tc}$-sestamibi than the background breast tissue. If the technologist observes a large mole or skin lesion on the breast that correlates with uptake on an MBI view, the radiologist should be notified to prevent unnecessary diagnostic work-up. Additionally, moles may need to be covered with gauze to prevent any skin tears if the positioning seems to cause unnecessary pulling in that area.

As previously mentioned, additional or substitute views may be needed to bring known lesions or breast concerns into the FOV. For lesions in the axilla, an exaggerated craniocaudal view or axillary tail view, performed per mammography guidelines (24), may help visualize axillary tissue. For lesions near the chest wall, a mediolateral or craniocaudal view with minimal immobilization may help visualize posterior breast tissue $(9,10)$.

\section{EXAMINATION INTERPRETATION}

Image findings should be reported by a qualified physician using the standardized MBI lexicon (25). Some institutions may prefer that the MBI examination be reviewed by a radiologist before patient dismissal, whereas this approach may not be practical for an institution with a high patient workflow. Our practice uses dedicated breast radiologists who batch-read MBI scans along with screening mammography scans. Though technical recalls are uncommon for MBI examinations, they may be indicated if the patient moved or the breast tissue is not completely visual- ized (e.g., from poor positioning). Occasionally, additional views may be requested to better assess an area of uptake. When possible, the patient should be recalled the same day to prevent the need for a second administration of ${ }^{99 \mathrm{~m}} \mathrm{Tc}$-sestamibi.

\section{CONCLUSION}

Our experience with MBI over the past 13 y has uncovered several factors that affect the quality of examinations. Best-practice considerations include proper patient preparation, including fasting and warming; scheduling during days 7-14 of the menstrual cycle when possible; use of a low-adhesion syringe and a saline flush when administering the dose, and training in mammography breastpositioning techniques to ensure optimal positioning. Artifacts and false-negative findings may be prevented if technologists receive proper training and are familiar with MBI best practices.

\section{DISCLOSURE}

This research was funded in part by grants from the Mayo Foundation and Mayo Center for Individualized Medicine. Carrie B. Hruska and Michael K. O'Connor receive royalties for licensed technologies per agreement between Mayo Clinic and Gamma Medica, a manufacturer of MBI systems. No other potential conflict of interest relevant to this article was reported.

\section{REFERENCES}

1. Rhodes DJ, Hruska CB, Conners AL, et al. Journal club: molecular breast imaging at reduced radiation dose for supplemental screening in mammographically dense breasts. AJR. 2015;204:241-251

2. Shermis RB, Wilson KD, Doyle MT, et al. Supplemental breast cancer screening with molecular breast imaging for women with dense breast tissue. AJR. 2016; 207:450-457.

3. Hruska CB, O'Connor MK. Nuclear imaging of the breast: translating achievements in instrumentation into clinical use. Med Phys. 2013;40:050901.

4. Bae MS, Moon WK, Chang JM, et al. Breast cancer detected with screening US: reasons for nondetection at mammography. Radiology. 2014;270:369377.

5. Conners AL, Jones KN, Hruska CB, Geske JR, Boughey JC, Rhodes DJ. Directconversion molecular breast imaging of invasive breast cancer: imaging features, extent of invasive disease, and comparison between invasive ductal and lobular histology. AJR. 2015;205:W374-W381.

6. Young E. A student's perspective on PET/MR: technologies can merge, but can technologists? J Nucl Med Technol. 2014;42:1-2.

7. Performance Measurements of Gamma Cameras. Arlington, VA: National Electrical Manufacturers Association; 2013. NEMA NU1-2012.

8. Tran TD, Swanson TN, Solberg CM, et al. One year overview of the molecular breast imaging clinical practice at Mayo Clinic [abstract]. J Nucl Med. 2016; 57(suppl 2):2676.

9. ACR practice parameter for the performance of molecular breast imaging (MBI) using a dedicated gamma camera. American College of Radiology website. https://www.acr.org/-/media/ACR/Files/Practice-Parameters/MBI.pdf?la=en. Adopted 2017. Accessed January 5, 2018.

10. Goldsmith SJ, Parsons W, Guiberteau MJ, et al. SNM practice guideline for breast scintigraphy with breast-specific gamma-cameras 1.0. J Nucl Med Technol. 2010;38:219-224.

11. Wackers FJ, Berman DS, Maddahi J, et al. Technetium-99m hexakis 2-methoxyisobutyl isonitrile: human biodistribution, dosimetry, safety, and preliminary comparison to thallium-201 for myocardial perfusion imaging. J Nucl Med. 1989;30:301-311. 
12. O'Connor MK, Hruska CB, Tran TD, et al. Factors influencing the uptake of ${ }^{99 \mathrm{~m}} \mathrm{Tc}$-sestamibi in breast tissue on molecular breast imaging. J Nucl Med Technol. 2015;43:13-20.

13. Kit for the preparation of technetium Tc $99 \mathrm{~m}$ sestamibi injection [package insert]. St. Louis, MO: Mallinckrodt Pharmaceuticals; 2015.

14. Hruska CB, Rhodes DJ, Conners AL, et al. Background parenchymal uptake during molecular breast imaging and associated clinical factors. AJR. 2015;204:W363-W370.

15. Hruska CB, Conners AL, Vachon CM, et al. Effect of menstrual cycle phase on background parenchymal uptake at molecular breast imaging. Acad Radiol. 2015;22:1147-1156.

16. Delmon-Moingeon LI, Piwnica-Worms D, Van den Abbeele AD, Holman BL, Davison A, Jones AG. Uptake of the cation hexakis(2-methoxyisobutylisonitrile)-technetium-99m by human carcinoma cell lines in vitro. Cancer Res. 1990; 50:2198-2202.

17. Hruska CB, O'Connor MK. Curies, and grays, and sieverts, oh my: a guide for discussing radiation dose and risk of molecular breast imaging. J Am Coll Radiol. 2015; $12: 1103-1105$.

18. Tran TD, Ellingson LR, Swanson TN, Solberg CM, O'Connor MK, Hruska CB. Molecular breast imaging: administered activity does not require adjustment based on patient size. J Nucl Med. 2017;58:784-790.
19. Swanson TN, Troung DT, Paulsen A, Hruska CB, O'Connor MK. Adsorption of ${ }^{99 \mathrm{~m}} \mathrm{Tc}$-sestamibi onto plastic syringes: evaluation of factors affecting the degree of adsorption and their impact on clinical studies. J Nucl Med Technol. 2013; 41:247-252.

20. Husain SS. Myocardial perfusion imaging protocols: is there an ideal protocol? J Nucl Med Technol. 2007;35:3-9.

21. Hruska CB, Weinmann AL, Tello Skjerseth CM, et al. Proof of concept for lowdose molecular breast imaging with a dual-head CZT gamma camera. Part II. Evaluation in patients. Med Phys. 2012;39:3476-3483.

22. Shermis RB, Redfern RE, Burns J, Kudrolli H. Molecular breast imaging in breast cancer screening and problem solving. Radiographics. 2017;37:13091606.

23. Berg WA. Nuclear breast imaging: clinical results and future directions. $J$ Nucl Med. 2016;57(suppl 1):46S-52S.

24. Kopans DB. Mammography positioning. In: Kopans DB, ed. Breast Imaging. 3rd ed. Philadelphia, PA: Lippincott, Williams, and Wilkins; 2007:281-322.

25. Conners AL, Hruska CB, Tortorelli CL, et al. Lexicon for standardized interpretation of gamma camera molecular breast imaging: observer agreement and diagnostic accuracy. Eur J Nucl Med Mol Imaging. 2012;39:971982. 